\title{
Sidney Kimmel Comprehensive Cancer Center at Johns Hopkins University
}

National Cancer Institute

\section{Source}

National Cancer Institute. Sidney Kimmel Comprehensive Cancer Center at Johns Hopkins

University. NCI Thesaurus. Code C39514.

The Sidney Kimmel Comprehensive Cancer Center at Johns Hopkins University has a mission to go beyond the cutting edge in science and medicine to perform the most advanced research and offer patients the very best therapies for their disease. Research scientists at the Center work closely with the clinicians to offer the latest diagnostic and therapeutic services to patients. It was designated as an $\mathrm{NCl}$ comprehensive cancer center in 1974. 